\title{
Hemşirelik Öğrencilerinin Bilimsel Araştırma Yapmaya Yönelik Kaygı ve Tutumlarının Belirlenmesi
}

\section{Determination of Anxiety and Attitude towards Doing Scientific Research of Nursing Students}

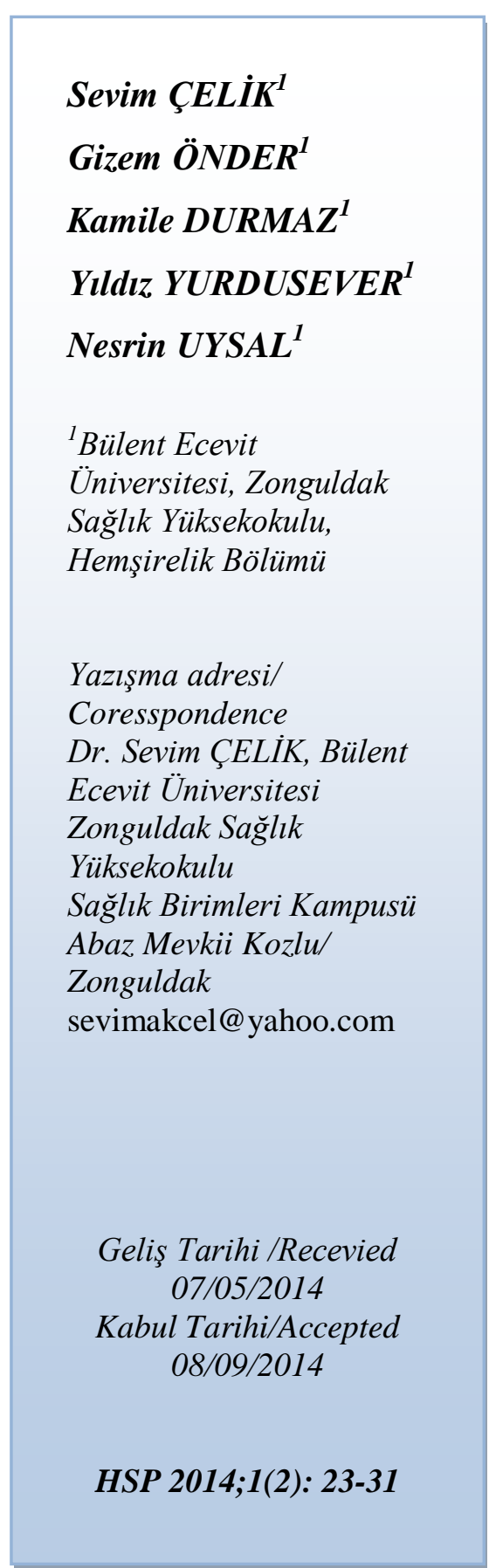

\section{ÖZET}

Amaç: $\mathrm{Bu}$ çalışmanın amacı, hemşirelik öğrencilerinin bilimsel araştırma yapmaya yönelik kaygı düzeylerini ve tutumlarını belirlemek ve etkileyen çeşitli değişkenler açısından incelemektir. Gereç ve Yöntemler: Kesitsel tipte tanımlayıcı araştırmanın örneklemini 70 öğrenci oluşturdu. Araștırmanın verileri; bilgi formu, Araştırmaya Yönelik Kaygı Ölçeği ve Araştırmaya Yönelik Tutum Ölçeği ile toplandı. Verilerin değerlendirilmesinde tanımlayıcı istatistikler, bağımsız değişkenlerde t-testi ve MannWhitney U testleri kullanıldı.

Bulgular: Öğrencilerin araştırmaya yönelik kaygı ölçeği puan ortalamasının $37.80 \pm 8.02$ olduğu saptand1. Öğrencilerin araştırmaya yönelik tutum ölçeği puan ortalaması $88.87 \pm 12.17$ olarak belirlendi. İstatistik dersi almayan öğrencilerin araştırma yapmaya yönelik kaygı düzeyleri daha yüksekti ( $p>0.05)$. İstatistik ve araştırma dersi alan, bilimsel araştırma yapan öğrencilerin araştırma yapmaya yönelik tutumları daha olumluydu ( $\mathrm{p}>0.05)$.

Sonuç: Çalışma, öğrencilerin araştırma yapmaya yönelik kaygı düzeyinin çok yüksek olmadığını ve araştırma yapmaya yönelik tutumlarının olumlu olduğunu göstermiştir.

Anahtar kelimeler: öğrenci, hemşire, araştırma kaygısı, araştırmaya yönelik tutum

\begin{abstract}
Aims: The aim of the study is to determine the anxiety and attitude related to doing the scientific research. It was aimed to investigate for various variables of the anxiety levels and attitudes. Materials and Methods: The sample of cross-sectional descriptive study was consisted of 70 students. Data were gathered using information form, Research Anxiety Scale and Research Attitude Scale. It was used descriptive statistics, independent samples t-test and Mann Whitney U test in data analysis. Results: The mean score for Research Anxiety Scale of the students was determined as $37.80 \pm 8.02$. The mean score for Research Attitude Scale was found as $88.87 \pm 12.17$. Anxiety levels towards doing research of students who not taking statistics course was higher $(\mathrm{p}>0,05)$. Attitudes toward doing research of students who taking statistics and doing scientific research was more positive $(p>0.05)$. Conclusion: The study show that anxiety levels towards doing research of the students are not very high and attitude towards doing research of students are positive.

Key words: Student, nurse, research anxiety, attitude towards
\end{abstract} research. 


\section{Giriş}

Bilimsel araştırma; bir konuda sorunların belirlenmesi, çözüm yollarının planlanması, uygulamaya konulması, sonuçlandırılması, sonuçların tartışılması ve yorumlanması ile ilgili olarak gerçekleştirilen planlı, amaçlı ve sistemli bilgi üretim etkinliklerinin tümüdür. ${ }^{1-5}$ Bilimsel araştırma yapabilmek ya da yapılan araştırmalardan etkin bir şekilde yararlanabilmek için bilgi ve beceri ile araştırmanın bilimsel ve toplumsal yaşamdaki yerinin anlaşılması önemlidir. $\mathrm{Bu}$ nedenle bilimsel tutum ve davranışların kazandırılması için bilimsel araştırma eğitiminin alınması gerekir. ${ }^{2,3,6}$

Türkiye'deki bilimsel araştırma eğitimi, daha ziyade lisansüstü eğitim için gerekli bir işlev olarak görülmektedir. ${ }^{4}$ Ancak sağlık bakımının kalitesinin arttırılmasında sağlık araştırmaları son derece önemli rol oynamaktadır. Klinik alanda çalışanların uygulamalarını geliştirmek, bakım sonuçlarını iyileştirmek için araştırmalara dahil olması tartışılmazdır. ${ }^{7}$ Ax ve Kincade $^{8}$ de yaptıkları bir çalışmada, öğrenci hemşirelerin, klinik uygulamaların gelişiminde araştırmaların etkili olduğunu belirttiklerini bildirmiştir. Yapılan farklı çalışmalarda ise, mezuniyet sonrası hemşirelerin klinik alanda bilgi, zaman ve destek yetersizliğinden dolayı araştırma verilerinden yararlanmaya karşı olumsuz tutum sergiledikleri belirtilmiştir. ${ }^{7,9} \mathrm{Bu}$ açıdan bakıldığında; hemşirelik mesleğini geliştirmek, mesleğin profesyonelleşmesine katkıda bulunmak, bakımda kaliteyi arttırmak, hemşirelerin otonomi ve güç sahibi olmalarını sağlamak için araştırma kültürünün lisans eğitimi sırasında kazandırılması, araştırmacı tutum ve davranışlarına sahip hemşireler yetiştirilmesi gerekmektedir. ${ }^{2,3,10}$

Türkiye'de hala lisans düzeyindeki araştırma eğitiminde ciddi eksiklik ve yetersizliklerin olduğu bilinmektedir. ${ }^{3,11}$ Ancak, son yıllarda hemşirelik bölümlerinde bilimsel araştırmaya yönelik dersler ile bu konuda önemli adımlar atılmış, araştırma yöntemleri konusunda var olan yayınlar arttırılmıştır. Yapılan çalışma sonuçları da lisans düzeyinde araştırma eğitimi verilmesinin, lisans öğrencilerinin araştırma yapmaya yönelik tutum ve yaklaşımlarının olumlu yönde etkilediğini göstermiştir. ${ }^{2,6,12}$ Konuya yönelik farklı çalışma bulgularında hala birçok öğrencinin araştırma konusunda yüksek kaygı düzeyine sahip oldukları ${ }^{13}$ ve araştırma yapmaya olumsuz baktıkları ${ }^{14}$ bildirilmiştir. Yüksek düzeyde araştırma kaygısının da, öz yeterlilik duygusunu azalttığı, kişilerin araştırma yapmaya yönelik olumsuz tutum geliştirmesine, araştırma yapılması gerektiğinde sıkılma ve rahatsızlık hissetme, araştırma yaparken kendini huzursuz hissetme gibi davranışların ortaya çıkmasına neden olduğu vurgulanmaktadır. ${ }^{6,15}$

Literatür incelendiğinde, hemşirelik öğrencilerinin araştırma yapmaya yönelik kayg1 ve tutumlarını inceleyen çalışma saptanmamıştır. Bu bağlamda, araştırma ile hemşirelik öğrencilerin bilimsel araştırma yapmaya yönelik kaygı düzeylerinin ve tutumlarının belirlenmesi ve bu kaygı düzeylerinin ve tutumlarının çeşitli değişkenler açısından incelenmesi amaçlanmıştır.

\section{Gereç ve Yöntemler}

Araştırmanın Şekli: $\mathrm{Bu}$ araştırma kesitsel tipte tanımlayıcı bir araştırma olarak gerçekleştirilmiştir.

Evren ve Örneklem: Araştırmanın evrenini, 2013-2014 Eğitim- Öğretim Yı1ı Bahar Yarıyılında Bülent Ecevit Üniversitesi Zonguldak Sağlık Yüksekokulu Hemşirelik Bölümü 4. sınıfta okuyan 97 öğrenci oluşturmuştur. Araştırmada örneklem seçimine gidilmemiş olup evrene ulaşılması 
hedeflenmiştir. Araştırmaya katılmaya gönüllü, Türkçe konuşup yazan, iletişim problemi olmayan, hemşirelikte araştırma dersini alan 70 öğrenci örneklem kapsamına alınmıştır. Araştırmaya katılmaya gönüllü olmayan ve araştırmanın yapıldığı tarihlerde devamsız olan 27 öğrenci örneklem dışı bırakılmıştır.

Verileri Toplama Aracı: Araştırmada veri toplama aracı olarak Tanıtıcı Bilgi Formu, Araştırmaya Yönelik Kaygı Ölçeği ve Araştırmaya Yönelik Tutum Ölçeği kullanılmıştır.

Tanıtıcı Bilgi Formu: Bu form; öğrencilerin yaş, cinsiyet, istatistik ve araştırma derslerini daha önce alıp almadığı, daha önce bir araştırma deneyimi olup olmadığı, hemşirelikle ilgili süreli yayın takip edip etmediği gibi özelliklerini sorgulayan; bir adet açık uçlu ve dokuz adet kapalı uçlu olmak üzere toplam 10 sorudan oluşmuştur.

Araştırmaya Yönelik Kaygı Ölçeği: Öğrencilerin araştırma kaygılarını belirlemek amacıyla Büyüköztürk ${ }^{16}$ tarafından geliştirilen, Cronbach alfa güvenirlik katsayısı $\alpha=.87$ olan ve 12 maddeden oluşan 5'li Likert tipi “Araştırmaya Yönelik Kaygı Ölçeği” kullanılmıştır. Araçta yer alan maddelere verilen yanıtlar, doğrudan kaygı durumunu yansitan ifadelerde $(1,5,6,7,9,10$, 12. maddeler) "tamamen katılıyorum"dan "hiç katılmıyorum"a doğru 5'den 1'e sayısal değerler verilerek puanlanmıştır. Doğrudan kaygı durumunu yansıtmayan (2, 3, 4, 8, 11. maddeler), tersine dönmüş ifadelerde ise bu işlemin tersi yapılmıştır. Böylece ölçekten alınan yüksek puan yüksek kaygıyı, düşük puan düşük kaygıyı göstermiştir. Ölçekten en az 12, en yüksek 60 puan alınabilmektedir. Bu araştırmada, ölçeğin güvenirlik katsayısı $\alpha=.83$ olarak hesaplanmıştır.

Araştırmaya Yönelik Tutum Ölçeği: Ölçek Köklü ${ }^{12}$ tarafindan geliştirilmiştir. 23 maddeden oluşan ve tamamen katılıyorum, katılıyorum, kararsızım, katılmıyorum ve hiç katılmıyorum şeklinde tutum seçenekleri olan 5'li Likert tipinde bir ölçektir. Ölçekte yer alan 23 maddenin 10 tanesi olumlu, 13'ü olumsuzdur. Olumlu maddeler 5'den 1'e, olumsuz maddeler ise 1'den 5' e puanlanmaktadır. Ölçekten en az 23, en fazla 115 puan alınabilmektedir. Yüksek puanlar, araştırmaya yönelik olumlu tutumu ifade etmektedir. Ölçeğin Cronbach alfa güvenirlik katsayısı $\alpha=.86$ 'dır. Bu araştırmada ölçeğin güvenirlik katsayısı $\alpha=.80$ olarak hesaplanmıştır.

Verilerin Toplanması: Öğrenciler araştırmanın amaçları, formların eksiksiz ve dikkatli bir şekilde doldurulması gerektiği, elde edilen verilerin sadece bilimsel amaçlı kullanılacağı konusunda bilgilendirildikten ve araştırmaya katılma onayları alındıktan sonra, veri formları öğrenciler tarafından araştırmacıların bulunduğu ortamda temel uygulamalı hemşirelik derslerinin bitiminde, gözlem altında doldurulmuştur. Anketler; Nisan- Mayıs 2014 tarihleri arasında öğrencilere uygulanmıştır. Öğrenciler 15-20 dakika içerisinde anketleri tamamladıktan sonra araştırmacılar tarafından geri toplanmıştır.

Verilerin Değerlendirilmesi: Verileri değerlendirmek için SPSS 18.0 istatistik paket programı kullanılmıştır. Araştırmada kişisel bilgilerin tespiti amacıyla yüzde, frekans ve ortalama gibi tanımlayıcı istatistiksel yöntemler kullanılmıştır. Öğrencilerin bilimsel araştırma yapmaya yönelik kaygı düzeylerini ve tutumları ile yaş, cinsiyet, daha önce istatistik ve araştırma 
derslerini alma durumları, araştırma deneyimlerini karşılaştırmak amacıyla bağımsız örneklem ttesti ve Mann Whitney U testi kullanılmıştır. Anlamlılık $\mathrm{p}<0.05$ düzeyinde değerlendirilmiştir.

Etik Yaklaşım: Araştırmaya başlamadan önce araştırmada kullanılan Araştırmaya Yönelik Kaygı Ölçeği’ni geliştiren yazardan ve araştırmanın yapılacağı kurumdan yazılı izin alınmıştır. Öğrencilerden ise araştırmanın amaçları, formların eksiksiz ve dikkatli bir şekilde doldurulması gerektiği, elde edilen verilerin sadece bilimsel amaçlı kullanılacağı konusunda bilgilendirildikten sonra sözel onayları alınmıştır.

\section{Bulgular}

Hemşirelik öğrencilerinin yaş ortalamasının $23.47 \pm 1.15$, çoğunluğunun kadın (\%68.6) olduğu ve istatistik dersi aldığ1 (\%92.9) belirlenmiştir. Aynı tablo incelendiğinde, öğrencilerin yarısının bilimsel araştırma yapma deneyimi olduğu (\%50), \%77.1'inin en az bir bilimsel araştırma okudukları, hemşirelikte yayın takibi/izleme durumlarının oldukça düşük oranda (\%18.6) olduğu bulunmuştur (Tablo 1).

Öğrenci hemşirelerin bilimsel araştırma yapmaya yönelik kaygı puan ortalaması $37.80 \pm 8.02$ olarak bulunmuştur. Tablo 2 incelendiğinde, öğrencilerin bilimsel araştırma yapmaya yönelik kaygı puan ortalamalarının orta düzeyde olduğu, tanıtıcı özellikleri ile araştırmaya yönelik kaygı ölçeği puan ortalamaları arasında istatistiksel anlamlı farklılık olmadığı saptanmıştır $(\mathrm{p}>0.05)$. Erkeklerin, istatistik dersi almayanların, bilimsel araştırma yapma deneyimi olanların, süreli yayınları takip edenlerin, bilimsel araştırma okuyanların kaygı puan ortalamalarının diğerlerine göre daha yüksek olduğu belirlenmiştir ( $p>0.05$ ) (Tablo 2).

Tablo 1. Öğrencilerin Tanıtıcı Özellikleri

\begin{tabular}{|c|c|c|c|}
\hline & & \multicolumn{2}{|c|}{$\mathbf{X} \pm \mathbf{S D}$} \\
\hline \multirow[t]{2}{*}{ Yaş } & & \multicolumn{2}{|c|}{$23.47 \pm 1.15$} \\
\hline & & $\mathbf{n}$ & $\%$ \\
\hline \multirow[t]{2}{*}{ Cinsiyet } & Kadın & 48 & 68.6 \\
\hline & Erkek & 22 & 31.4 \\
\hline \multirow[t]{2}{*}{ İstatistik dersi alma durumu } & Almış & 65 & 92.9 \\
\hline & Almamış & 5 & 7.1 \\
\hline \multirow[t]{2}{*}{ Bilimsel araştırma yapma deneyimi } & Var & 35 & 50.0 \\
\hline & Yok & 35 & 50.0 \\
\hline \multirow[t]{2}{*}{ Hemşirelikte süreli yayınları izleme } & Evet & 13 & 18.6 \\
\hline & Hayır & 57 & 81.4 \\
\hline \multirow[t]{2}{*}{ Bilimsel araştırma okuma durumu } & Okumuş & 54 & 77.1 \\
\hline & Okumamış & 16 & 22.9 \\
\hline
\end{tabular}


Tablo 2. Öğrencilerin Tanıtıcı Özellikleri ile Araştırmaya Yönelik Kaygı Ölçeği (AYKÖ) Puan Ortalamalarının Karşılaştırılması

\begin{tabular}{lllcc}
\hline & & \multicolumn{1}{|c}{$\begin{array}{c}\text { AYKÖ } \\
\text { Cinsiyet }\end{array}$} & $\begin{array}{c}\text { İstatistiksel } \\
\text { test* }\end{array}$ & p \\
& Kadın & $37.33 \pm 6.38$ & $\mathrm{Z}=-0.507$ & $\mathrm{p}=0.62$ \\
& Erkek & $38.81 \pm 10.88$ & & \\
\hline İstatistik dersi alma durumu & Almış & $37.70 \pm 8.09$ & $\mathrm{Z}=-0.308$ & $\mathrm{p}=0.75$ \\
& Almamış & $39.00 \pm 7.64$ & & \\
\hline Bilimsel araştırma yapma deneyimi & Var & $37.94 \pm 9.03$ & $\mathrm{t}=0.14$ & $\mathrm{p}=0.88$ \\
& Yok & $37.65 \pm 6.99$ & & \\
\hline Hemşirelikte süreli yayınları izleme & Evet & $38.00 \pm 6.97$ & $\mathrm{Z}=-0.303$ & $\mathrm{p}=0.76$ \\
& Hayır & $37.75 \pm 8.29$ & & \\
\hline Bilimsel araştırma okuma durumu & Okumuş & $38.25 \pm 8.22$ & $\mathrm{Z}=-0.785$ & $\mathrm{p}=0.43$ \\
& Okumamış & $36.25 \pm 7.30$ & & \\
\hline
\end{tabular}

*Z: Mann Whitney U testi *t: Student t testi

Öğrencilerin araştırma yapmaya yönelik tutum ölçeğinden $88.87 \pm 12.17$ puan alarak araştırma yapmaya yönelik tutumlarının olumlu olduğu saptanmıştır. Tablo 3 incelendiğinde, bilimsel araştırma yapmaya yönelik tutumları ile öğrencilerin tanıtıcı özellikleri arasında istatistiksel anlamlı farklılık saptanmadığı görülmektedir. Ayrıca, araştırma kapsamındaki erkeklerin, istatistik dersi alanların, bilimsel araştırma yapma deneyimi olanların, süreli yayınları izleyenlerin, daha önce bilimsel araştırma okuyanların, bilimsel araştırma yapmaya yönelik tutumlarının daha olumlu olduğu belirlenmiştir ( $p>0.05)$ (Tablo 3). 
Tablo 3. Öğrencilerin Tanıtıcı Özellikleri ile Araştırmaya Yönelik Tutum Ölçeği Alt Boyutları ve Toplam Puan Ortalamalarının Karşılaştırılması

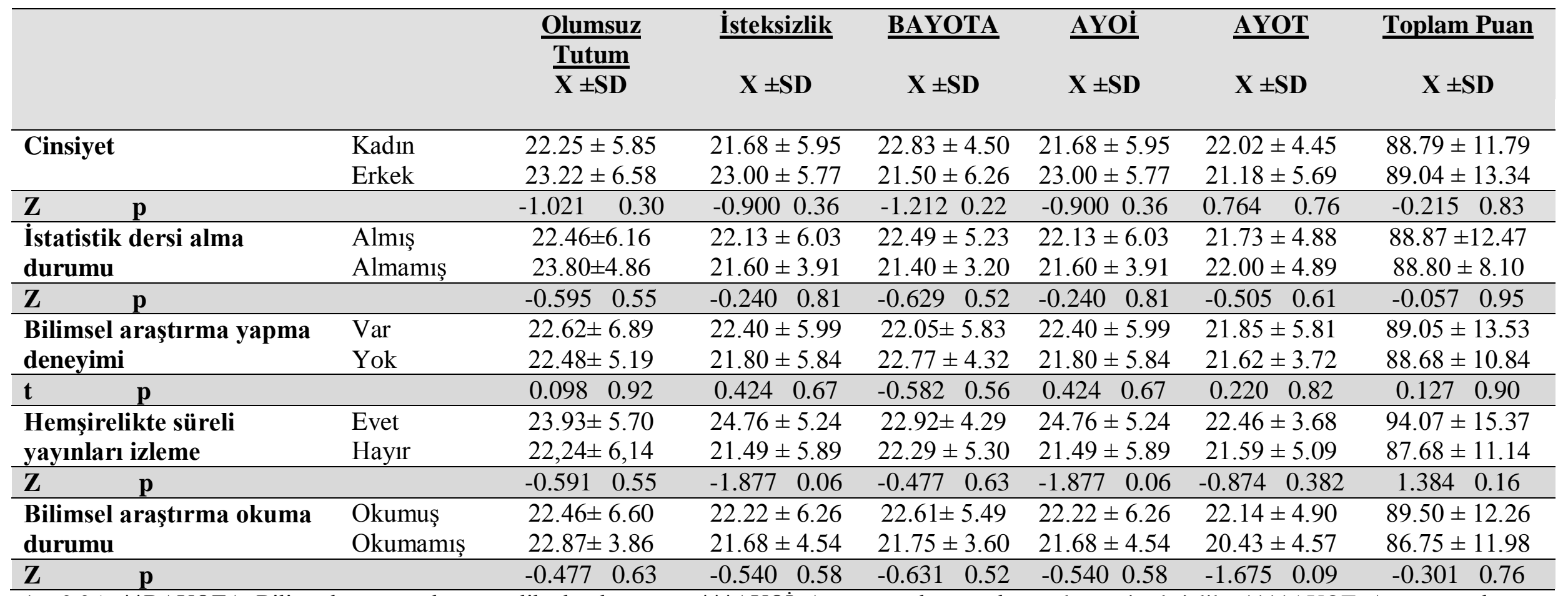

$* \mathrm{p}<0.05 * *$ BAYOTA: Bilimsel araştırmalara yönelik olumlu tutum ***AYOİ: Araştırmacılara yardımcı olmaya isteksizlik ****AYOT: Araştırmacılara yönelik olumlu tutum 


\section{Tartışma}

Araştırma, lisans düzeyinde eğitim alan öğrenci hemşirelerin araştırma yapma kaygılarının orta düzeyde olduğunu göstermiştir. Elde edilen veriler, önceki araştırma verileri ile paralellik göstermektedir. Önceki yıllarda Yılmaz ve Çokluk'un ${ }^{6}$ fen edebiyat fakültesi mezunları üzerinde yaptığı çalışmada da, öğrencilerin araştırma kaygılarının çok yüksek olmadığı belirlenmiştir. Saracaloğlu ${ }^{3}$ ile Bayar ve arkadaşlarının ${ }^{4}$ lisansüstü öğrencilerde yaptığı bir çalışmalarda, lisansüstü eğitim alan öğrencilerin, araştırma kaygısının düşük düzeyde olduğu saptanmıştır. Aldıkları araştırma eğitim ile araştırma bilgisini etkili bir şekilde kullanmaları beklenen hemşire adaylarının, kaygı düzeylerinin düşük olması gerekir. Türkiye'de hemşirelik araştırmalarının yapılması sürecinde, hemşirelerin ve öğrencilerin araştırmacılara veri toplanmasını kolaylaştıracak şekilde destek olmamalarında öğrencilerin araştırma yapma sürecinde çok yüksek olmasa da kaygı yaşamalarının etkili olduğu kanısındayız.

$\mathrm{Bu}$ güncel araştırmada öğrencilerin cinsiyetleri ile araştırma yapmaya yönelik kaygı puan ortalamaları arasında anlamlı farklılık saptanmamıştır. Diğer yandan erkek öğrencilerin bilimsel araştırma yapmaya yönelik kaygılarının daha yüksek olduğu saptanmıştır. Bökeoğlu ve Yılmaz ${ }^{17}$ Bayar ve arkadaşları ${ }^{4}$ ile Saracaloğlu ve arkadaşlarının ${ }^{2}$ yaptıkları çalışmalarda ise öğrencilerin araştırma yapma kaygılarının cinsiyetlere göre farklılık göstermediği saptanmıştır. Bu araştırma bulgusunun önceki yıllarda yapılan araştırma bulguları ile paralellik gösterdiği belirlenmiştir.

Araştırma sonuçlarına göre istatistik dersi alma durumu ile öğrencilerin bilimsel araştırma yapmaya yönelik kaygı durumları arasında anlamlı bir farklılık oluşmamıştır. Ancak, istatistik dersi almayan öğrencilerin kaygı puan ortalamalarının daha yüksek olduğu saptanmıştır. $\mathrm{Bu}$ sonuç gruplardaki öğrenci sayılarının birbirine yakın olmamasından kaynaklanmış olabilir. Elde edilen bu bulgu Yılmaz ve Çokluk ${ }^{6}$ 'un, Saracaloğlu ${ }^{3}$, Saracaloğlu ve arkadaşlarının ${ }^{2}$ yaptıkları çalışma sonuçları ile paralellik göstermiştir.

Yapılan bu güncel araştırmaya göre, öğrencilerin bilimsel araştırma yapmaya yönelik tutumlarının olumlu olduğu saptanmıştır. Björkström ve $\operatorname{arkadaşlar1~}^{9}$ da, hemşirelik öğrencilerinin araştırmaya karşı tutumlarının olumlu olduğunu belirtmişlerdir.

Araştırma kapsamındaki öğrencilerin cinsiyetleri ile bilimsel araştırma yapmaya yönelik tutumları arasında anlamlı farklılık saptanmamıştır. Elde edilen bu bulgu, gençlerin cinsiyet fark1 gözetmeksizin araştırmalara olumlu yaklaşımlarından kaynaklanabilir. Ancak bu araştırmada, erkek öğrencilerin bilimsel araştırma yapmaya yönelik tutumlarının daha olumlu olduğu saptanmıştır. Saracaloğlu ${ }^{3}$ yaptığı çalışmada da araştırmaya yönelik tutum puanlarının cinsiyete göre farklılaşmadığ 1 saptamıştır. Saracaloğlu nun ${ }^{18}$ beden eğitimi öğretmeni adayları üzerinde gerçekleştirdiği başka bir çalışmada kız öğrencilerin, Gürgan ve $\operatorname{Er}^{19}$ tarafından yapılan araştırmada ise erkek öğrencilerin tutumlarının daha olumlu olduğu saptanmıştır.

Yapılan bu çalışmada, istatistik dersi alanların araştırma yapmaya yönelik tutumları daha olumlu bulunmuştur $(\mathrm{p}>0.05)$. Bu durum istatistik dersi almış olmanın araştırmayı anlamaya etkisi ile araştırmaya yönelik tutum arasındaki ilişkinin varlığı ile açıklanabilir. Güncel çalışmanın bulguları önceki yıllarda yapılan çalışma bulguları ile de paralellik göstermiştir. Saracaloğlu ve arkadaşlarının ${ }^{2}$ çalışmalarında ise araştırma tutumunun öğrencilerin istatistik dersi alma durumuna göre farklılaşmadığı saptanmıştır. Saracaloğlu'nun ${ }^{3}$ yaptığı bir başka araştırmada ise, istatistik dersi almanın anlamlı şekilde araştırma yapmaya yönelik tutumları olumlu etkilediği belirlenmiştir. Buna göre istatistik dersi alan gençlerin araştırma yapmaya ilişkin tutumları daha olumludur. 
Araştırmada bilimsel araştırma okuyan öğrencilerin araştırma yapmaya yönelik tutumları istatistiksel anlamlı olmasa da daha olumlu bulunmuştur. Bu bulgu, hemşire olarak uygulama alanlarında görev yapmaya başladıklarında bakımlarında, kanıta dayalı uygulamaları gerçekleştirecekleri düşündürdüğünden oldukça sevindiricidir. Collins ve Onwuegbuzie ${ }^{20}$ de bilimsel araştırmaları okuyanların araştırma yapmakta daha başarılı olduklarını belirtmiştir.

Araştırmadaki diğer bir bulguya göre, daha önce bir araştırma deneyimi olan ya da araştırmaya katkıda bulunan öğrencilerin bilimsel araştırma yapmaya yönelik daha olumlu tutum geliştirdikleri saptanmıştır. Ancak tutum puan ortalamalarında gözlenen fark istatistiksel olarak anlamlı bulunmamıştır. Saracaloğlu'nun ${ }^{3}$ yaptığı çalışmada da araştırma deneyimi olan ve olmayanların araştırmaya yönelik tutum puanlarında farklılaşmanın olmadı̆̆ı saptanmıştır. Saracaloğlu ve arkadaşlarının² yaptıkları çalışmada ise araştırma deneyiminin araştırmaya yönelik tutumları anlamlı şekilde etkileyen bir değişken olduğu bulunmuştur.

\section{Sonuç ve Öneriler}

Araştırma öğrenci hemşirelerin bilimsel araştırma yapmaya yönelik kaygılarının orta düzeyde ve tutumlarının da olumlu olduğunu göstermiştir.

Araştırma bulguları doğrultusunda;

- Üniversitelerin hemşirelik öğretim planlarında araştırma kültürünü olumlu yönde destekleyen araştırma eğitiminin verilmesi,

- Öğrencilere lisans eğitimleri sırasında en az bir kez bilimsel araştırma yapma deneyiminin sağlanması,

- Araştırma kaygılarını azaltmak ve olumlu tutumlarını sürdürmek üzere, çalışmalarının ödüllendirilmesi ve bu çalışmaları sunabilecekleri ortamların oluşturulması,

- Öğrencilerin lisans eğitimleri sırasında bilimsel kongre ve sempozyumlara katılma olanaklarının sağlanması önerilmektedir.

\section{Kaynaklar}

1. Karasar N. Bilimsel Araştırma Yöntemi. 15. Baskı. Ankara: Nobel Yayın Dağıtım; 2005.

2. Saracaloğlu AS, Varol SR, Ercan İE. Lisansüstü eğitim öğrencilerinin araştırma kaygıları, araştırma ve istatistiğe yönelik tutumları ile araştırma yeterlikleri arasındaki ilişki. Buca Ĕ̌itim Fakültesi Dergisi 2005; Özel Sayı 1: 187-199.

3. Saracaloğlu AS. Lisansüstü öğrencilerin akademik güdülenme düzeyleri, araştırma kaygıları ve tutumları ile araştırma yeterlikleri arasındaki ilişki. Yüzüncü Yll Üniversitesi Ĕ̆gitim Fakültesi Dergisi 2008; 5(2): 179-208

4. Bayar V, Bayar A, Eğmir E, Ödemiş Sİ, Kayır G. Lisansüstü eğitimi alan öğrencilerin bilimsel araştırma yapmaya yönelik kaygı düzeyleri. VI. Ulusal Lisansüstü Eğitim Sempozyum Kitapçığı, 14-15 Mayıs 2013, Sakarya,ss.90-96

5. Erdoğan S. Araştırmaya Giriş ve Araştırma Süreci. İçinden: Erdoğan S, Nahcivan N, Esin N, editörler. Hemşirelikte Araştırma: Süreç, Uygulama ve Kritik. İstanbul: Nobel Tıp Kitabevleri; 2014.ss. 3-4.

6. Yılmaz K, Çokluk Ö.Fen - Edebiyat Fakültesi mezunlarının araştırma kaygı düzeyleri. Abant İzzet Baysal Üniversitesi Dergisi 2010; 10(1):1-9. 
7. Sabzvari S, Kauser S, Khuwaja AK. Experiences, attitudes and barriers towards research amongst junior faculty of Pakistani medical universities. BMC Medical Education 2009; 9:68-74.

8. Ax S, Kincade E. Nursing students' perceptions of research: usefulness, implementation and training. Journal of Advanced Nursing 2001; 35: 161-170

9. Björkström ME, Johansson IS, Hamrin EK, Athlin EE. Swedish nursing students' attitudes to and awareness of research and development within nursing. J Adv Nurs. 2003;41(4):393-402.

10. Unrau YA, Beck AR. Increasing research self-efficacy among students in professional academic programs. Innovative Higher Education 2004; 28(3): 187-204.

11. Şenol S. Araştırma ve Örnekleme Yöntemleri. Ankara: Nobel Yayınları; 2012.

12. Köklü N. Araştırmaya Yönelik Bir Tutum Ölçeğinin Geliştirilmesi. Eğitim ve Bilim 1992; 16(86): 27-36.

13. Onwuegbuzie AJ, Wilson VA. Statistics anxiety: nature, etiology, antecedents, effects, and treatments-comprehensive review of the literature. Teaching in Higher Education 2003; 8(2): 195-209.

14. Blischak D, Cheek M. A lot of work keeping everything controlled: a class research project. American Journal of Speech-Language Pathology 2001; 10:10-16

15. Lei, SA. Factors changing attitudes of graduate school students toward an introductory research methodology course. Education 2008; 128(4): 667-85.

16. Büyüköztürk Ş. Araştırmaya yönelik kaygı ölçeğinin geliştirilmesi. Eğitim Yönetimi 1997; 3(4): 453-64.

17. Bökeoğlu, ÇO, Yılmaz K. Üniversite öğrencilerinin eleştirel düşünmeye yönelik tutumları ile araştırma kaygıları arasındaki ilişki. Kuram ve Uygulamada Eğitim Yönetimi 2005; 41: 60-65

18. Saracaloğlu AS. Beden eğitimi öğretmeni adaylarının araştırmaya yönelik tutumları ve deneyimleri ile araştırma başarıları arasındaki ilişki. Gazi Üniversitesi Beden Ĕgitimi ve Spor Bilimleri Dergisi 2005; X (4): 13-32.

19. Gürgan U, Er KO. Öğretmen adaylarının internet kullanımına ve araştırmaya yönelik tutumları arasındaki ilişkilerin çeşitli değişkenler açısından belirlenmesi. 17. Ĕgitim Bilimleri Kongresi, 1-3 Eylül 2008, Sakarya.

20. Collins KMT, Onwuegbuzie AJ. Relationship between reading ability and achievement in a graduate-level research methodology course.paper presented at the annual meeting of the American Educational Research Association, New Orleans, LA, April.2000[cited 2014 August 15] Avaliable from: http://www.unco.edu/ae-extra/2008/8/onwuegbuzie.html 